\title{
Developmental dynamics of cone photoreceptors in the eel Phillippa B Cottrill1 ${ }^{1}$, Wayne L Davies ${ }^{1,2}$, Ma'ayan Semo ${ }^{1}$, James K Bowmaker ${ }^{1}$, David M Hunt ${ }^{1}$ and Glen Jeffery*1
}

\author{
Address: ${ }^{1}$ UCL Institute of Ophthalmology, 11-43 Bath Street, London, EC1V 9EL, UK and ${ }^{2}$ Nuffield Laboratory of Ophthalmology, University of \\ Oxford, Level 5-6, West Wing, John Radcliffe Hospital, Headley Way, Oxford, OX3 9DU, UK \\ Email: Phillippa B Cottrill - p.cottrill@ucl.ac.uk; Wayne L Davies - w.davies13@gmail.com; Ma'ayan Semo - m.semo@ucl.ac.uk; \\ James K Bowmaker - j.bowmaker@ucl.ac.uk; David M Hunt - d.hunt@ucl.ac.uk; Glen Jeffery* - g.jeffery@ucl.ac.uk \\ * Corresponding author
}

Published: 21 December 2009

BMC Developmental Biology 2009, 9:71 doi:10.1|86/|47|-2|3X-9-7|
Received: 2 June 2009

Accepted: 21 December 2009

This article is available from: http://www.biomedcentral.com/|47|-2|3X/9/7|

(c) 2009 Cottrill et al; licensee BioMed Central Ltd.

This is an Open Access article distributed under the terms of the Creative Commons Attribution License (http://creativecommons.org/licenses/by/2.0), which permits unrestricted use, distribution, and reproduction in any medium, provided the original work is properly cited.

\begin{abstract}
Background: Many fish alter their expressed visual pigments during development. The number of retinal opsins expressed and their type is normally related to the environment in which they live. Eels are known to change the expression of their rod opsins as they mature, but might they also change the expression of their cone opsins?

Results: The Rh2 and Sws2 opsin sequences from the European Eel were isolated, sequenced and expressed in vitro for an accurate measurement of their $\lambda_{\max }$ values. In situ hybridisation revealed that glass eels express only rh2 opsin in their cone photoreceptors, while larger yellow eels continue to express rh2 opsin in the majority of their cones, but also have $<5 \%$ of cones which express sws 2 opsin. Silver eels showed the same expression pattern as the larger yellow eels. This observation was confirmed by qPCR (quantitative polymerase chain reaction).

Conclusions: Larger yellow and silver European eels express two different cone opsins, rh2 and sws2. This work demonstrates that only the Rh2 cone opsin is present in younger fish (smaller yellow and glass), the sws 2 opsin being expressed additionally only by older fish and only in $<5 \%$ of cone cells.
\end{abstract}

\section{Background}

Eels (such as the European eel, Anguilla anguilla) change their habitat several times during their life cycle and undergo two distinct metamorphoses that involve morphological, physiological and behavioural changes [1,2]. Eels are catadromous teleosts which are probably spawned in the blue water of the Sargasso Sea [3], possibly at depths of $<200 \mathrm{~m}$ [3]. The embryo becomes a leptocephalus (translucent leaf-shaped larva) and spends 1-2 years [3] drifting with the Gulf Stream into the North Atlantic. Leptocephali travel the $\sim 6000 \mathrm{~km}$ to the European continental shelf with its more green coastal water, where they metamorphose into glass eels, one of two juvenile forms. As elvers (pigmented glass eels) and then as yellow eels (the larger juvenile form), they travel up European rivers and spend 6-20 years in a yellow/brown stained fresh water environment, where they grow and mature as a freshwater species. Subsequently, mature eels must cross the Atlantic Ocean to return to the Sargasso Sea to spawn. Both just prior to and during this migration they undergo 'silvering', usually described as a second metamorphosis but which is more correctly a pubertal event [4], when they become sexually mature adult fish. As sexually mature European eels have never been caught, 
it is thought that they become fully mature either on the last part of their journey or on reaching their destination. During this life cycle, the photic environment of the eel changes considerably, moving from blue deep sea to green coastal waters, into yellow/brown shallow freshwater and back to blue deep sea again.

Many fish alter their complement of visual pigments during development and this can be attributed in most cases to environmental changes during the life cycle [5-7]. Shallow dwelling fish with access to a wide visual spectrum usually express a full complement of visual opsins, a rod pigment and four cone pigments. Deeper dwelling benthic (living $>1 \mathrm{~km}$ down) species which have limited or no access to down-welling sunlight have dispensed with many or all of the cone opsins and retained only rod photoreceptors. These often have very extended or multiple layered outer segments for maximal photon catch of attenuated sunlight or bioluminescence [8]. Eels experience more changes to their photic environment than most fish species, and are known to switch the rod visual pigment (rh1) on maturation from a "fresh water" form to a "deep-sea" form $[9,10]$. Wavelength sensitivity is also affected by a change in the ratio of vitamin A1- and A2derived chromophores used to produce rhodopsin (i.e. vitamin A1-based pigment) and porphyropsin (vitamin A2-based pigment) $[11,12]$. Maturation is also accompanied by an increase in rod domination in the retina $[12,13]$ arising from the proliferation of rod progenitors [14].

The retinae of most larval teleosts which later undergo a metamorphic event (termed indirect development), contain only cone photoreceptors; with rods being added later after metamorphosis [15-17]. It had been thought that eels were the exception to this rule [13], but work by Omura [18], showed that cones are present in very early ( $<2$ week old) leptocephali. Omura also showed that older leptocephali ( $>2$ weeks) possess a pure rod retina from which the cones must have been lost [18]. However, in postmetamorphic glass eels, the retina contains both rods and cones [19-21]. Eels are therefore known to change the photosensitivity of their rod photoreceptors as well as the photoreceptor composition of the retina during their life cycle. Two spectrally distinct cone classes have been identified [19] but the classes of cone opsin expressed, the timing of cone development, and the distribution of cone types in the retina are largely unknown. This study sets out to determine when changes in cone opsin expression might occur.

\section{Results \\ Cone opsins}

Microspectrophotometric (MSP) analysis of the retinae of glass, yellow and silver eels [19] demonstrated the pres- ence of two types of cones, a middle wavelength-sensitive (MWS) class and a short wavelength-sensitive (SWS) class. The former was found at all three developmental stages but showed a variable $\lambda_{\max }$ that arose from changes in the proportions of the A1 pigment rhodopsin and the A2 pigment porphyropsin that were present. The $\lambda_{\max }$ of the pigment as a pure rhodopsin was estimated to be at $525 \mathrm{~nm}$, consistent with the values found by other workers, allowing for differences in chromophore ratio [20,21]. In contrast, the SWS class was found only in yellow and silver eels. Again, the exact wavelength varied slightly according to the proportions of rhodopsin (A1) and porphyropsin (A2) present, with an estimated $\lambda_{\max }$ for pure rhodopsin of $435 \mathrm{~nm}$.

To identify the opsin genes responsible for the pigment present in these MWS and SWS cones, eel retinal cDNA was used. Only two opsin sequences were obtained which corresponded by BLAST analysis to the rh2 and sws 2 opsin coding sequences present in other species. No fragments corresponding to either the lws or sws 1 opsin genes were found.

The identity of these sequences was further confirmed using phylogenetic analysis. As shown in Figure 1, the rh2 and sws 2 eel sequences are placed into clades with orthologues from other species. The sequences have been deposited in GenBank with accession numbers of FJ515778 for rh2 and FJ515779 for sws2.

\section{Peak sensitivities of cone pigments}

To correlate the expressed cone opsin genes with the cone classes identified by MSP, full-length eel rh2 and sws2 sequences were expressed and regenerated with 11-cis-retinal, the $\lambda_{\max }$ values were obtained by spectrophotometry. As shown in Figure 2, the rh2 sequence resulted in a pigment with a $\lambda_{\max }$ value of $525 \mathrm{~nm}$, identical therefore to the value obtained by MSP for the MWS cones. The sws 2 sequence gave a pigment with a $\lambda_{\max }$ of $446 \mathrm{~nm}$, which is somewhat red-shifted compared to the value of $435 \mathrm{~nm}$ obtained by MSP for the SWS cones. Such differences may be encountered when comparing between in vitro and in situ $\lambda_{\max }$ values and it was concluded therefore that the MWS and SWS cones express the rh2 and sws 2 pigments respectively $[5,22]$.

\section{Spatial and temporal development of cones classes}

In situ hybridisation (ISH) was performed with rh2 and sws 2 sense and anti-sense probes. These were derived from the 5' or 3' UTR and coding region of the RH2 cDNA, and gave a positive signal in a large proportion of cells in the cone layer. Using the 3 ' end of the sws 2 coding sequence a positive signal to the anti-sense probe was observed in a sub-set of cone cell bodies (Figure 3). No signal was obtained for either of the sense (control) probes. 


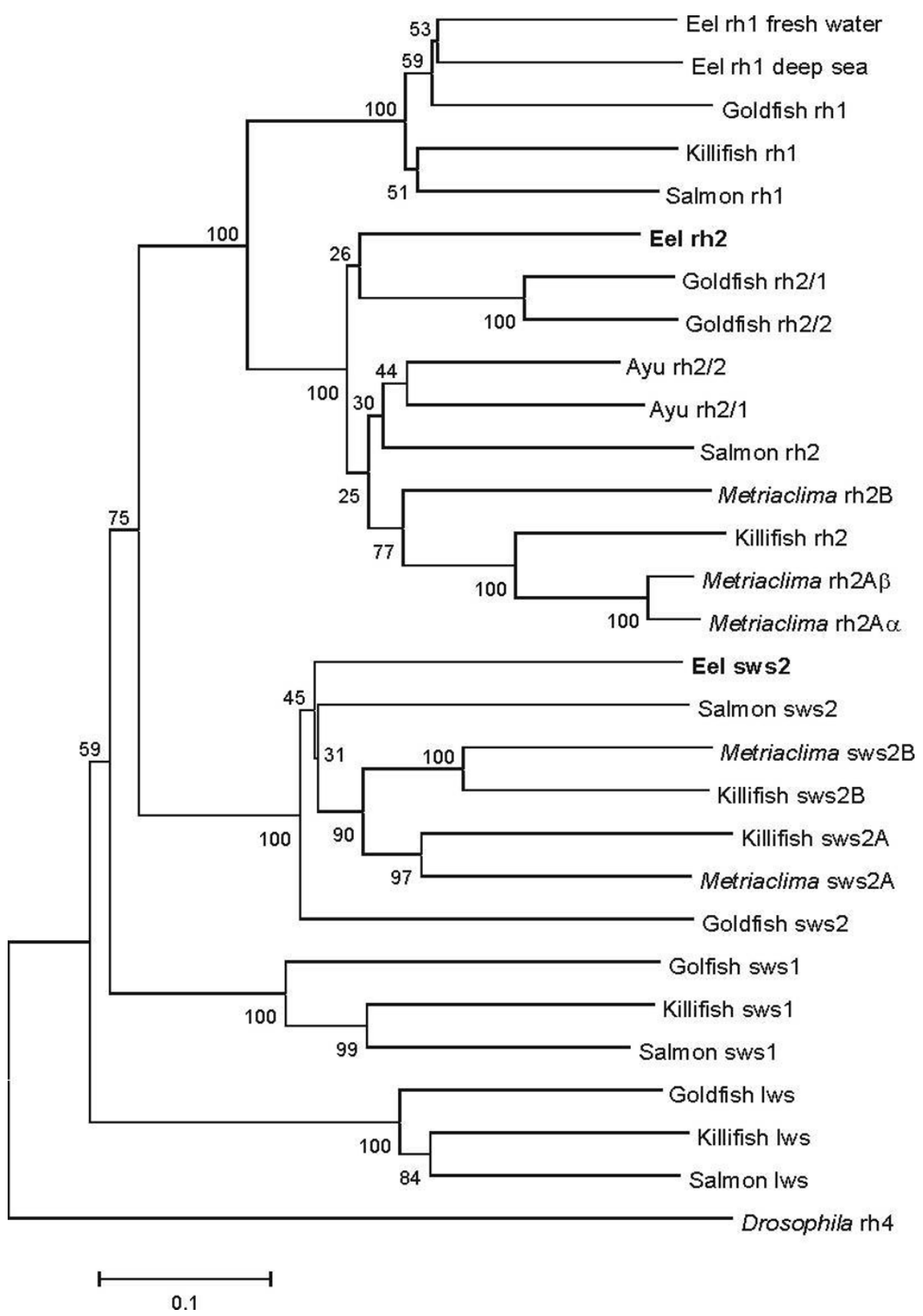

Figure I

Phylogenetic tree for visual opsin gene sequences. The tree was generated by the neighbour-joining method [35], using amino acid sequences aligned by ClustalW [36]. The degree of support for internal branching was assessed by bootstrapping with 1000 replicates using the MEGA2 computer package [37]. The calibration bar is equivalent to 0.1 substitutions per site. GenBank accession numbers for the sequences (from top to bottom) are Eel rh I "freshwater", L78007; Eel rh I "deep sea", L78008; Goldfish rhI, LI 1863; Killifish rhI, AY296738; Salmon rh2, AF201470; Eel rh2, FJ5I5778; Goldfish rh2/I, LII866, Goldfish rh2/2, LI I865; Ayu rh2/2, AB098704; Ayu rh2/I, AB098703; Salmon rh2, AY2I4I32; Metriaclima zebra rh2B, DQ0088652; Killifish rh2, AY296739; Metriaclima zebra rh2A $\beta$, DQ088650; Metriaclima zebra rh2Aa, DQ08865I; Eel sws2, FJ5 I5779; Salmon sws2, AY2I4I34; Metriaclima zebra sws2B, AF247I I8; Killifish sws2B, AY296736; Killifish sws2A, AY296737; Metriaclima zebra sws2A, AF247I I4; Goldfish sws2, LI I864; Goldfish sws I, D85863; Killifish sws I, AY296735; Salmon sws I, AY2 14I33; Goldfish Iws, LI I867; Killifish Iws, AY296740; Salmon Iws, AY2 I4I 3 I; Drosophila rh4, NM_057353. 
As is usual for fish retinae, the cone cells are arranged as a continuous monolayer situated above the outer limiting membrane, between the outer nuclear layer $(\mathrm{ONL}$, the nuclei of the rod cells) and the rod outer segments themselves (ROS). The signal indicating the presence of $r h 2$ opsin mRNA transcript can be seen in all cone cells in the glass eel, and in the majority of cone cells in the yellow and silver eels. The sws 2 probe also highlighted cones in the monolayer. However, in contrast to the MWS cones, sws2-containing cells were restricted to the retinae from older eels, with none in any of the glass eels (20 fish), a few in the elvers/small yellow eels ( 2 of 19 fish $<300 \mathrm{~mm}$ in length), but were present in all the larger yellow fish ( 8 fish $>300 \mathrm{~mm}$ in length) and in all silver eels ( 3 animals $>770 \mathrm{~mm}$ in length). The spatial frequency of the SWS cones is also lower than the MWS cones, with each SWS cone sited at discrete spacings compared to the continuous monolayer of MWS cones. The distance between SWS cones varied widely (partly according to fish size), from a value of 1 in 5 found in several mid-sized yellow eels, to 1 in 12 cells in one of the silver eels. Most mid-sized yellow eels measured showed average MWS cone spacings of $7 \pm 1.7 \mu \mathrm{m}$; whilst for the SWS cones, the same fish gave values of $45 \pm 15 \mu \mathrm{m}$. The silver and very large yellow eels were more variable (50-90 $\mu \mathrm{m}$ between SWS cells, with standard deviations of up to $40 \%$, typically $68 \pm 23 \mu \mathrm{m}$ ). For mid-sized yellow eels, this was a linear spacing of approximately one in every 6-7 cones, equivalent to an array frequency of approximately 1 in 30 .

\section{Relative levels of opsin expression}

\section{Cone pigments}

Quantification of the levels of rh2 and sws2 opsin transcripts by qPCR are in general agreement with the findings of the in situ hybridisation experiments, as is shown in Figure $4 \mathrm{~A}$. The level of $r h 2$ opsin mRNA was slightly lower in
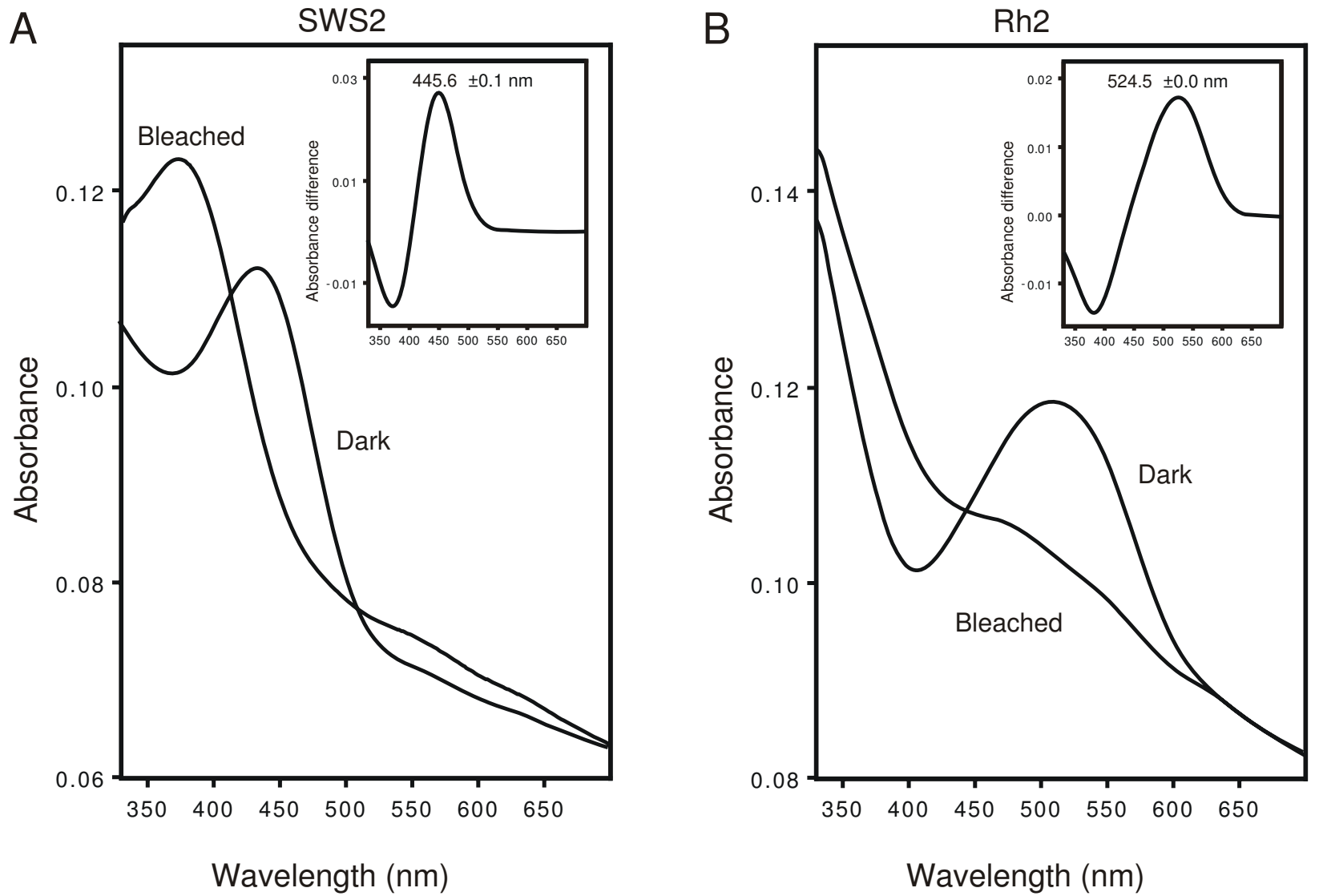

Figure 2

In vitro expression of eel cone opsins. A. Expression of the eel sws 2 opsin protein gave a calculated $\lambda_{\max }$ of $445.6 \pm 0.1 \mathrm{~nm}$, in agreement with the previously measured $\lambda_{\max }$ of $435 \mathrm{~nm}$ allowing for the differences in chromophores. B. Expression of the eel rh2 opsin protein gave a calculated $\lambda_{\max }$ of $524.5 \pm 0.0 \mathrm{~nm}$, which is almost identical with the measured $\lambda_{\max }$ of $525 \mathrm{~nm}$. The close agreement between the MSP measurements and those of the in vitro expressed protein confirms that the isolated opsin sequences are those expressed by the cones. 


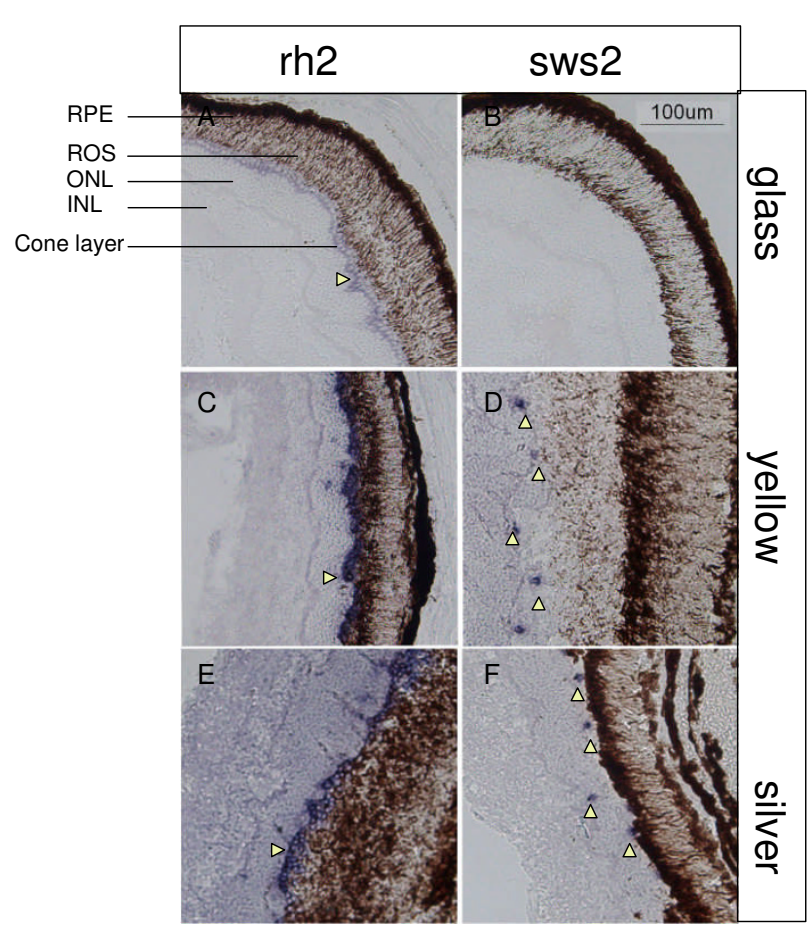

Figure 3

Distribution of opsin-expressing cone cells in eel retina. Transverse sections of eel retina from different developmental stages showing localisation of cone opsin expression as detected by in situ hybridisation of the $5^{\prime}$ end of $r h 2$ or sws 2 opsin mRNA. Cone cell bodies in the eel are arranged in a single layer between the inner nuclear layer (INL) and the rod outer segments (ROS). Glass eel: (A) the layer of cone cells expresses rh2 opsin (horizontal arrowhead), (B) sws2 opsin expression was not detected in the glass eel retina. Yellow eel: (C) the layer of cone cells expressing rh2 opsin (horizontal arrowhead), (D) occasional cone cells expressing sws 2 opsin (vertical arrowheads). Silver eel: (E) monolayer of cone cells expressing rh2 opsin (horizontal arrowhead), (F) occasional cone cells express sws 2 opsin (vertical arrowheads). Scale bar is $100 \mu \mathrm{m}$, all panels are to same scale. RPE, retinal pigment epithelium; ROS, rod outer segments; ONL, outer nuclear layer; INL, inner nuclear layer.

glass eels than in yellow and silver eels, where the levels were very similar. A surprising finding was the presence of expressed sws 2 opsin mRNA in glass eels when no SWS2containing cones were evident by in situ hybridization staining. Across all three stages, the level of sws 2 message was substantially lower than $r h 2$ message, consistent with the relative paucity of SWS2-containing cones compared to MWS cones.

\section{Rod pigments}

It has been previously shown [12] that the sexual maturation of both the European and American eel is accompanied by an increase in rod domination of the retina and a shift in absorbance maxima of the rod photoreceptors to a shorter wavelength; this shift is the result of a switch in expression in rod opsin from the "freshwater" (fwo) to the "deep sea" (dso) form $[9,10]$. The presence of this switch was confirmed by qPCR (Figure 4B) where expression of the dso form, although just detectable in glass and yellow eels, is significant only in silver eels where it represents around $60 \%$ of the total expressed rod opsin. The levels of the fwo form show a significant increase from glass to yellow stage, and this level is maintained in the silver eels despite the simultaneous expression at a higher level of the dso form.

The ratio of cone to rod opsin expression reflects the rod dominant nature of the eel retina. Even at the glass eel stage, a ratio of rod to cone $(r h 2+s w s 2)$ opsin mRNA expression is 17:1, and this rises to 30:1 in yellow eels and to $121: 1$ in silver eels (with expression of fwo and dso forms of rod opsin combined). Morphologically (Figure 5), rods contribute an increased proportion of the retina in yellow eels compared to glass eels, with an approximate doubling in the thickness of the outer nuclear layer. This increase does not however continue into the silver eel stage, so the substantial increase in the rod to cone opsin ratio seen at this stage is likely to reflect an increase in the relative production of rod opsin mRNA during the switch over from fwo to dso forms.

\section{Discussion}

We have demonstrated here that the European eel (Anguilla anguilla) changes opsin gene expression more times during its lifetime than had previously been reported. It was shown by Omura [18] that cones cells are present in very early leptocephali; whilst older leptocephali possess a pure rod retina [23]. It was also shown by Hope et al. [9], and quantified by Zhang et al. [10], that rod photoreceptors start to express the dso form of rod opsin as the animal undergoes puberty (silvering) before migration from fresh to salt water. Glass eels have a mixed retina with rh2 opsin expressed in cones [19], indicating that they have already made a change from the pure rod retina of the leptocephali. This probably occurs as they move from the deep sea into the shallower waters of the continental shelf and estuaries. A second change in cone opsin expression then occurs as they either move into the rivers or remain longer in the estuaries. Instead of a monolayer of cone photoreceptor cells expressing only the rh2 pigment, occasional sws2 opsin-expressing cones appear within the monolayer. It could not be determined whether an rh2 opsin-expressing cone changes to express sws2 opsin (as happens during the switch in expression from fwo to dso forms of rod opsin $[9,10]$ ); or if new cones which express the sws 2 pigment are inserted at intervals into the monolayer. The result appears as an array of SWS-expressing cones interspersed within the MWS cone monolayer. 
The results of the qPCR experiments did not fully confirm the findings of the in situ hybridisations on the varying amounts of sws 2 cone opsin in the different life stages of the eel. Whilst no cells containing sws 2 opsin mRNA were detected by in situ hybridisation in the glass stage eels, sws 2 opsin sequence was detected in these samples by qPCR, which is commonly believed to be a more sensitive detection method. From the in situ hybridisation results, sws 2 opsin expression did not appear to start until well into the yellow stage (greater than $300 \mathrm{~mm}$ length), and continued at a similar level into the silver stage. However, qPCR, suggested that the levels of sws 2 opsin expression in the yellow and silver eel was only about 4 to 5 -fold higher than in the glass eel stage, as can be seen in figure 4A. A possible explanation for this could be that sws 2 opsin message is transcribed as a default at a very low level by all cone cells, but at too low a level to be detected by in situ hybridisation. It is thought that expression of the sws 1 opsin gene is the default pathway for mouse cone cells [24] and it could be that the sws 2 message is the default in eel cones. In this case, after the eel reaches a certain size, the sws 2 opsin transcript is turned off in most cells which continue to express $r$ rh opsin and are spectrally identifiable as MWS cones, but is upregulated in specific cells which then become detectable by in situ hybridisation as sws2-expressing cells and by microspectrophotometry as SWS cones. The calculated transcription copy numbers suggested that the level of $r h 2$ expression was approximately 40 -fold higher for all stages than that for sws2, which is in good agreement with the apparent 30-fold fewer sws 2 opsin-expressing cells seen by in situ hybridisation.

There are two possible mechanisms for the changes in opsin gene expression. The most probable mechanism is that the existing cone cell changes the opsin type it is expressing. This is already known to occur in the rod cells of eels when they switch from expression of fwo to expression of dso [25]. It has also been shown to occur in rainbow trout [26], where single cones change from expression of sws 1 to sws 2 opsin. Alternatively, newly generated photoreceptors expressing the sws 2 opsin could be generated from Müller glial-associated retinal progenitors that can function as multipotent retinal stem cells [26] and inserted into the photoreceptor layer [27].

\section{Conclusions}

In this paper, we have shown that European eels express only two classes of cone opsin, rh2 and sws2. The rh2 class is expressed in young animals, whereas the sws 2 opsin is expressed only by older animals. Spectral analysis of in vitro expressed pigments demonstrates that their absorbance peaks correspond to the values obtained by in situ MSP for the MWS and SWS cones. This was further confirmed by in situ hybridization where it was shown that a class of rh2-expressing cones is present as a monolayer in the retina at the glass eel stage. The sws2-expressing cones appear later at the yellow eel stage as occasional cells within this monolayer. The presence of two cone classes at the later stages of pre-pubertal development is consistent with a relatively broad-spectrum light environment present in the rivers and estuaries that the eels occupy prior to full sexual maturation and migration into the deep ocean.

\section{Methods \\ Animals}

European eels (Anguilla anguilla L.) were obtained from different sources according to their size. Glass eels were obtained from http://www.glasseel.com. Elvers and small yellow eels were collected by the authors from the river Thames, with the permission of the Environment Agency. Larger yellow eels were obtained from a registered Thames eel fisherman (Gary Hillar). Very large yellow and silver eels were obtained from Billingsgate fish market. All animals were treated in line with the guidelines laid out in the code of practice for the housing and care of animals used in scientific procedures (Animals (Scientific Procedures) Act 1986). Animals that were not used immediately on arrival were maintained in large aerated tanks with natural light or, if in a dark room, on a 12L:12D light cycle using fluorescent aquarium light tubes. Immediately before use animals were anaesthetised by immersion in MS222 (1:2000 w/v in water) before being culled following standard procedures. Mature silver status was assessed by eye and body length measurements which were fed into the formula of Pankhurst [28], and only those animals with a Eye Index scores $>6.5$ were considered true silver eels.

\section{Identification of gene sequences}

Total RNA was isolated from the heads of glass eels, or eyecups (lacking lenses) of slightly larger animals or the retina/RPE of large animals, using Tri Reagent (Sigma). The mRNA was transcribed into cDNA using the SMART RACE Amplification kit (Clontech Laboratories Inc) according to the manufacturer's instructions. Opsin sequences were PCR-amplified using degenerate primers designed to conserved areas of opsin sequences. The 5' and $3^{\prime}$ ends were obtained by RACE using the anchor primers in the SMART RACE cDNA Amplification kit paired with specific primers designed to previously isolated sequence.

\section{In situ hybridisation}

Eyes isolated from animals that had been culled following standard procedures, were fixed overnight in $4 \%$ paraformaldehyde, transferred to $30 \%$ sucrose and the lens removed (from larger eyes). After overnight incubation in sucrose they were snap frozen in OCT compound (Vector Labs) and stored at $-80^{\circ} \mathrm{C}$ before being sectioned on a cryostat. 
A.

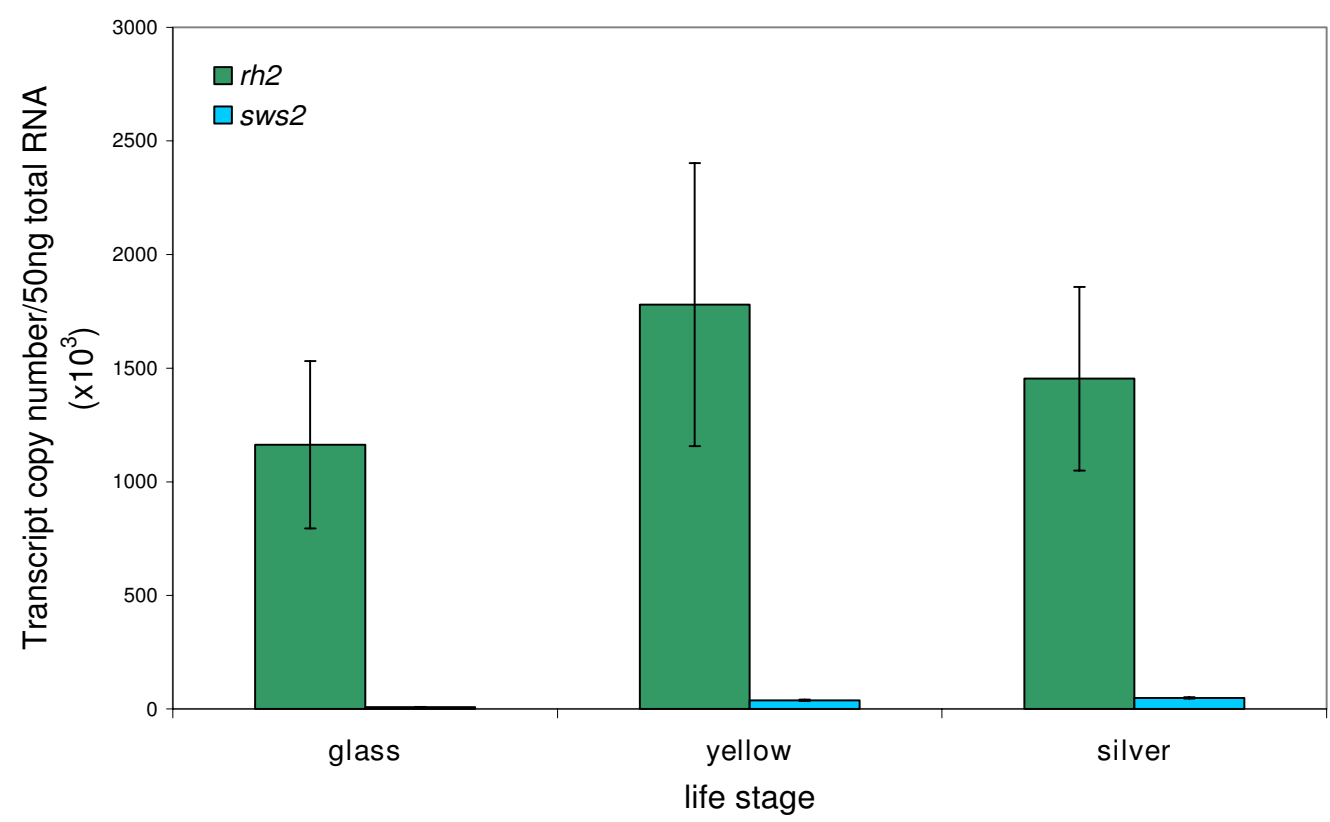

B.

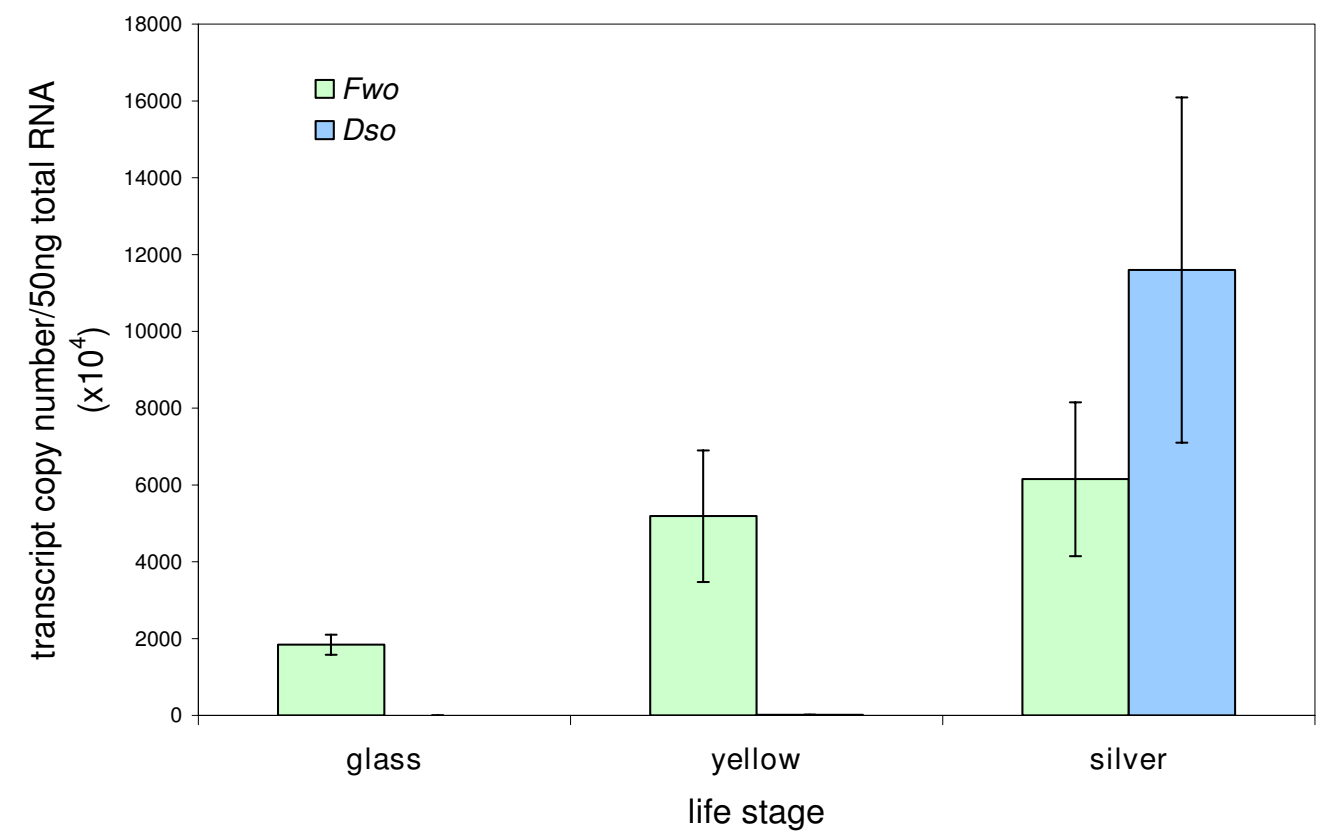

Figure 4

Changes in expression levels of opsins at different life stages of the eel. A. The expression level of $r h 2$ and sws 2 cone opsin transcripts as copy numbers per $50 \mathrm{ng}$ total RNA. The level of green opsin is approximately equivalent in the different life stages, but the amount of blue opsin doubles between the glass and silver stage. B. The expression of the two rod $(r h l)$ opsin transcripts as copy numbers per $50 \mathrm{ng}$ total RNA. The level of fwo transcript appears to increase slightly between the glass and later stages, but the amount of dso transcript increases markedly between the glass and silver life stages. Error bars show standard deviations which are necessarily large for the non-glass eels as each sample represents a point on a continuum. 


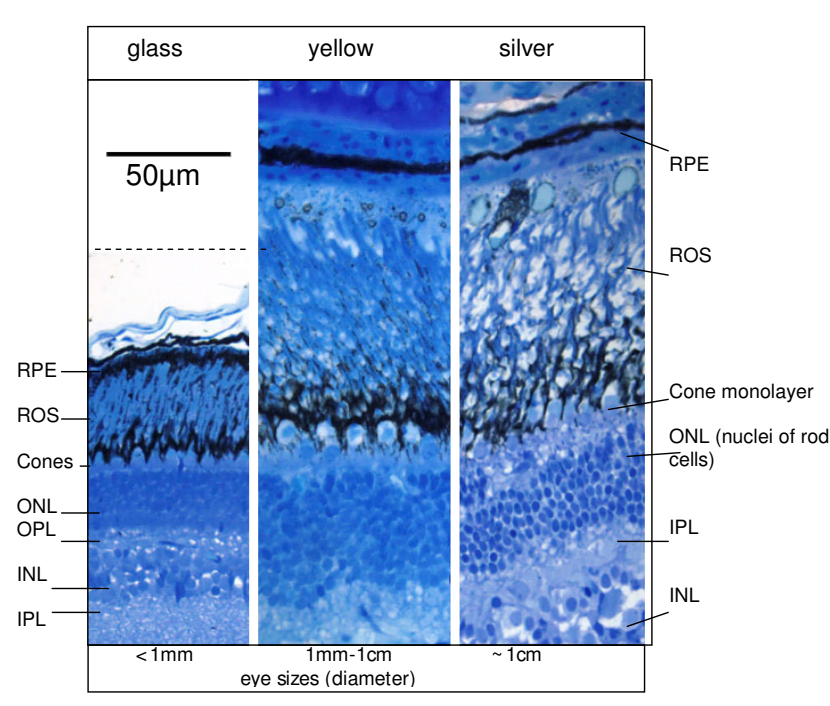

Figure 5

Changes in the retina in different life stages of the eel. $2 \mu \mathrm{m}$ thick plastic-embedded sections of eel retina from different life stages were stained with Richardson's Stain. It can be clearly seen that the thickness of the retina, and especially of the outer nuclear layer (rod cell nuclei), doubles between the glass and the silver stages of the life cycle. The size of the eye itself changes dramatically between the different stages, as indicated in the bottom panel, increasing tenfold in diameter. Such changes must necessitate large scale remodelling of the retinal components. RPE, retinal pigment epithelium; ROS, rod outer segments; ONL, outer nuclear layer; INL, inner nuclear layer; OPL, outer plexiform layer; IPL, inner plexiform layer. Scale bar $=50 \mu \mathrm{m}$, all histology panels are to the same scale.

Probes were prepared from $3^{\prime}$ and $5^{\prime}$ opsin sequences $\left(5^{\prime}\right.$ or 3' UTR and coding region of the rh 2 CDNA; and the $3^{\prime}$ end of the sws 2 coding sequence) cloned into the pGEM $\mathrm{T}_{\text {(easy) }}$ vector (Promega). The inserts were made into riboprobes labelled with DIG using the SP6/T7 Transcription kit (Roche Ltd.). The DIG-labelled probes were hybridised to $10 \mu \mathrm{m}$ frozen tissue sections and hybridised probe was visualised using BM purple (Roche Ltd.). Sections were examined using an Olympus BX50 microscope and photographs taken with a Nikon digital camera DXM 1200.

\section{qPCR}

The RNA extraction protocol followed was as above using Tri Reagent (Sigma) or Trizol (Invitrogen), with mRNA transcribed into cDNA using Superscript III (Invitrogen) with oligo d(T) primer (Invitrogen). First strand cDNA was prepared from $1 \mu \mathrm{g}$ total RNA extracted from heads of glass eels, or eyecups lacking lenses of larger fish. The visual pigments were quantified using gene-specific primers; which were designed, using the primer 3 program on the NCBI website, to amplify $300 \mathrm{bp}$ fragments. Internal controls (housekeeping genes) used were as previously published: mitochondrial cytochrome $\mathrm{b}$ (intron-free) and acidic ribosomal phosphoprotein P0 (ARP) from Welt- zein et al. [29], and glucose 6 phosphate dehydrogenase (g6pdh) and 6-phosphogluconate dehydrogenase (6pgdh) from Pierron et al. [30]. A minimum of three reactions were performed on a minimum of three animals of each of the three sizes ( 24 glass, 18 yellow and 4 silver). Raw data was analysed using the DART-PCR spreadsheet [31], and $\mathrm{R}_{0}$ values calculated. For normalisation purposes a normalisation factor was calculated from the $R_{0}$ values of internal control genes using geNORM [32], and the resulting values used to normalise the results obtained for the test genes. Standard curves were plotted using cloned genes and their calculated copy numbers for the reactions in parallel with the test samples.

\section{In vitro opsin expression}

This was performed as previously described $[33,34]$. The full-length coding region of the rh2 and sws 2 opsins were isolated by PCR using specific primers and cloned into the eukaryotic expression plasmid pMT4. The resulting plasmid was used to transiently transfect HEK-293T cells. The recombinant visual pigments were extracted and column purified with the Rho1D4 antibody. Pigments were regenerated by incubation with 11-cis-retinal, and analysed by a Spectronic Unicam UV500 dual-beam spectrophotometer. After 3 independent recordings, pigments were bleached by exposure to bright fluorescent light for 30 minutes and re-analysed. The bleached pigment spectra were subtracted from the dark spectra to produce a difference spectrum and a peak absorbance $\left(\lambda_{\max }\right)$ value using standard computer programs. The resulting visual spectra were overlaid by visual pigment templates and best-fit spectral curves were obtained.

\section{Histology}

Eyes for embedding in plastic were fixed in fresh $2 \%$ formaldehyde, 2\% glutaraldehyde in PBS, dehydrated through an ascending alcohol series and embedded in Technovit 7100 resin (Heraeus), as per manufacturer's instructions. After the blocks had hardened, sections were cut at $2 \mu \mathrm{m}$ on a microtome using a glass knife before being stained with Richardson's stain and mounted in DPX.

\section{Authors' contributions}

All authors have read and approved the final manuscript. The in vitro expression work was done by WLD who generated figure 2 and provided degenerate primers for the lws and sws 1 sequences. MS obtained the sequence of the rh2 opsin, $\mathrm{PBC}$ isolated the sws 2 sequence, performed the ISH and qPCR, and initially drafted the manuscript. DMH generated figure 1 and modified the manuscript; GJ, DMH and JKB obtained the funding, and guided the project and write-up of this manuscript.

\section{Acknowledgements}

The authors would like to acknowledge the following: Dr Livia Carvalho for help with the initial in vitro expression, Dr Marjia Mihelec for help with the 
in situ protocol, Ms Jaimie Hoh Kam for instructions on cryoembedding and cryosectioning, and Prof Rosalie Crouch, Medical University of South Carolina, USA, for the provision of I I-cis-retinal. The project was funded by a project grant from the Biotechnology and Biological Sciences Research Council of the UK awarded to GJ, DMH and JKB.

\section{References}

I. Berry L, Brookes D, Walker B: The problem of the migration of the European eel (Anguilla anguilla). Science Progress 1972, 60:465-485.

2. Tesch FW: The eel: biology and management of anguillid eels London: Chapman and Hall; 1977.

3. van Ginneken VJT, Maes GE: The European eel (Anguilla anguilla, Linnaeus), its lifecycle, evolution and reproduction: a literature review. Rev Fish Biol Fisheries 2005, I 5:367-398.

4. Aroua S, Schmitz M, Baloche S, Vidal B, Rousseau K, Dufour S: Endocrine evidence that silvering, a secondary metamorphosis in the eel, is a pubertal rather than a metamorphic event. Neuroendocrinology 2005, 82:221-232.

5. Bowmaker JK, Loew ER: Vision in Fish. In The Senses: a Comprehensive Reference I Vision Edited by: Masland RH, Albright TD. Oxford: Elsevier; 2008:53-76.

6. Douglas RH: The ecology of teleost fish visual pigments: a good example of sensory adaptation to the environment? In Ecology of Sensing Edited by: Barth FG, Schmid A. Berlin: Spriner Verlag; 2001:215-235.

7. Partridge JC, Cummings ME: Adaptations of visual pigments to the aquatic environment. In Adaptive mechanisms in the ecology of vision Edited by: Archer SN, Djamgoz MBA, Loew ER, Partridge JC, Valerga S. Dordrecht: Kluwer; 1999:25I-283.

8. Wagner H-J, Frohlich E, Neglishi K, Collin S: The eyes of deep-sea fish II. Functional morphology of the retina. Progess in Retinal and Eye Research 1998, 17:637-685.

9. Hope AJ, Partridge JC, Hayes PK: Switch in rod opsin gene expression in the European eel, Anguilla anguilla (L.). Proceedings of the Royal Society of London Series B Biological Sciences 1998, 265:869-874.

10. Zhang H, Futami K, Horie N, Okamura A, Utoh T, Mikawa N, et al: Molecular cloning of fresh water and deep-sea rod opsin genes from Japanese eel Anguilla japonica and expressiona analyses during sexual maturation. FEBS Lett 2000, 469:39-43.

II. Carlisle DB, Denton E): A change in visual pigments in the life of the freshwater eel. Journal of Physiology 1957, I39:8.

12. Beatty DD: Visual pigments of the american eel Anguilla rostrata. Vision Res 1975, I5:77|-6.

13. Pankhurst NW: Retinal development in larval and juvenile European eel Anguilla anguilla. Canadian Journal of Zoology 1984 62:335-343.

14. Omura Y, Tsuzuki K, Sugiura M, Uematsu K, Tsukamoto K: Rod cells proliferate in the eel retina throughout life. Fisheries Science 2003, 29:924-928.

15. Evans BI, Fernald RD: Metamorphosis and fish vision. J Neurobiol 1990, 2 I: 1037-1052

16. Adler R, Raymond PA: Have we achieved a unified model of photoreceptor cell fate specification in vertebrates? Brain Research 2008, I | 92: | 34- I50.

17. Mader MM, Cameron DA: Photoreceptor differentiation during retinal development, growth, and regeneration in a metamorphic vertebrate. J Neurosci 2004, 24: I |463-I |472.

18. Omura Y, Kasumsa U, Tachiki H, Furukawa K, Satoh H: Cone Cells appear also in the Retina of Eel Larvae. Fisheries Science 1997, 63:1052-1053.

19. Bowmaker JK, Semo M, Hunt DM, Jeffery G: Eel visual pigments revisited: The fate of retinal cones during metamorphosis. Vis Neurosci 2008, 25: I-7.

20. Gordon J, Shapley RM, Kaplan E: The eel retina. Receptor classes and spectral mechanisms. Journal of General Physiology 1978, 71:123-138

21. Damjanovic I, Byzov AL, Bowmaker JK, Gacic Z, Utina IA, Maximova EM, et al: Photopic vision in eels: evidences of color discrimination. Ann NY Acad Sci 2005, 1048:69-84.

22. Parry JW, Poppalasundaram S, Bowmaker JK, Hunt DM: A novel amino acid substitution is responsible for spectral tuning in a rodent violet-sensitive visual pigment. Biochemistry 2004 43:8014-8020.
23. Blaxter JHS, Staines M: Pure-cone retinae and retinomotor responses in larval teleosts. Journal of the Marine Biological Association UK 1970, 50:449-460.

24. Ng L, Hurley JB, Dierks B, Srinivas M, Salto C, Vennstrom B, et al.: A thyroid hormone receptor that is required for the development of green cone photoreceptors. Nat Genet 2001, 27:94-98.

25. Wood P, Partridge JC: Opsin Substitution Induced in Retinal Rods of the Eel (Anguilla anguilla (L.)): A Model for G-Protein-Linked Receptors. Proceedings: Biological Sciences 1993, 254:227-232

26. Cheng CL, Flamarique IN: Chromatic organization of cone photoreceptors in the retina of rainbow trout: single cones irreversibly switch from UV (SWSI) to blue (SWS2) light sensitive opsin during natural development. J Experimental Biology 2007, 2 I 0:4 I 23-4I35.

27. Raymond P, Barthel L, Bernardos R, Perkowski J: Molecular characterization of retinal stem cells and their niches in adult zebrafish. BMC Developmental Biology 2006, 6:36.

28. Pankhurst NW: Relation of visual changes to the onset of sexual maturation in the European eel Anguilla anguilla (L.). Journal of Fish Biology 1982, 2 I: I 27-I 40.

29. Weltzien FA, Pasqualini C, Vernier P, Dufour S: A quantitative real-time RT-PCR assay for European eel tyrosine hydroxylase. General and Comparative Endocrinology 2005, I 42: I 34- I 42.

30. Pierron F, Baudrimont M, Bossy A, Bourdineaud JP, BrFthes D, Elie P, et al.: Impairment of lipid storage by cadmium in the European eel (Anguilla anguilla). Aquatic Toxicology 2007, 8 I:304-3 I I.

31. Peirson SN, Butler JN, Foster RG: Experimental validation of novel and conventional approaches to quantitative real-time PCR data analysis. Nucl Acids Res 2003, 31 :e73.

32. Vandesompele J, De Preter K, Pattyn F, Poppe B, Van Roy N, De Paepe A, et al: Accurate normalization of real-time quantitative RT-PCR data by geometric averaging of multiple internal control genes. Genome Biol 2002 , 3:research0034.I-research0034.II.

33. Shand J, Davies WL, Thomas N, Balmer L, Cowing JA, Pointer M, et al.: The influence of ontogeny and light environment on the expression of visual pigment opsins in the retina of the black bream, Acanthopagrus butcheri. J Exp Biol 2008, 21 I:1495-1503.

34. Davies WL, Cowing JA, Carvalho LS, Potter IC, Trezise AE, Hunt DM, et al.: Functional characterization, tuning, and regulation of visual pigment gene expression in an anadromous lamprey. FASEB J 2007, 2 I:27। 3-2724.

35. Saitou N, Nei M: The neighbor-joining method: a new method for reconstructing phylogenetic trees. Mol Biol Evol 1987, 4:406-425.

36. Higgins DG, Thompson JD, Gibson TJ: Using CLUSTAL for multiple sequence alignments. Methods Enzymol 1996, 266:383-402.

37. Kumar S, Tamura K, Jakobsen IB, Nei M: MEGA2: molecular evolutionary genetics analysis software. Bioinformatics 200I, | 7:| 244- | 245 .

Publish with Biomed Central and every scientist can read your work free of charge

"BioMed Central will be the most significant development for disseminating the results of biomedical research in our lifetime. "

Sir Paul Nurse, Cancer Research UK

Your research papers will be:

- available free of charge to the entire biomedical community

- peer reviewed and published immediately upon acceptance

- cited in PubMed and archived on PubMed Central

- yours - you keep the copyright
BioMedcentral 